\title{
Acidobacteria appear to dominate the microbiome of two sympatric Caribbean Sponges and one Zoanthid
}

\author{
Aileen O'Connor-Sánchez ${ }^{1}$, Adán J Rivera-Domínguez', César De los Santos-Briones', Lluvia K López-Aguiar², \\ Yuri J Peña-Ramírez $z^{3}$ and Alejandra Prieto-Davo ${ }^{2^{*}}$
}

\begin{abstract}
Background: Marine invertebrate-associated microbial communities are interesting examples of complex symbiotic systems and are a potential source of biotechnological products.

Results: In this work, pyrosequencing-based assessment from bacterial community structures of sediments, two sponges, and one zoanthid collected in the Mexican Caribbean was performed. The results suggest that the bacterial diversity at the species level is higher in the sediments than in the animal samples. Analysis of bacterial communities' structure showed that about two thirds of the bacterial diversity in all the samples belongs to the phyla Acidobacteria and Proteobacteria. The genus Acidobacterium appears to dominate the bacterial community in all the samples, reaching almost $80 \%$ in the sponge Hyrtios.
\end{abstract}

Conclusions: Our evidence suggests that the sympatric location of these benthonic species may lead to common bacterial structure features among their bacterial communities. The results may serve as a first insight to formulate hypotheses that lead to more extensive studies of sessile marine organisms' microbiomes from the Mexican Caribbean.

Keywords: Marine-invertebrate microbiome, 165 rRNA pyrotags, Mexican Caribbean, Sponge-microbiome, Zoanthid-microbiome, Marine sediments-microbiome

\section{Background}

In recent years, the studies on sponge-associated microbial communities have had an increased attention of the scientific community. The two most important reasons for this are: (I) the secondary metabolites produced by the sponge microbiome have shown very promising pharmaceutical and biotechnological activities (e.g. as antibacterial, anthelmintic, anti-inflammatory, or antitumor agents, or neurosuppressors) [1]. (II) The spongemicrobe interactions are interesting examples of complex symbiotic systems [2].

Sponges are the simplest multicellular animals and the most ancient metazoans [3]. The microorganisms they contain are integral components of their body and can account for up to $40 \%$ of their volume [4]. As filter feeders,

\footnotetext{
* Correspondence: apdavo@unam.mx

${ }^{2}$ Facultad de Química - Unidad Académica Sisal, Universidad Nacional Autónoma de México, Puerto de abrigo s/n, Municipio de Hunucmá, 97356 Sisal, Yucatán, México

Full list of author information is available at the end of the article
}

sponges are capable of turning over many thousands of liters of water per day; prokaryotes, as well as nano- and pico-eukaryotes, are the most important components of the sponge diet, but they also have other roles, as pathogens or symbionts, or in stabilizing sponge skeleton or processing metabolic waste $[4,5]$. Sponge-microbe interactions are complex, and some evidence supports high host specificity among many of these associations [6], suggesting that each sponge exerts a selective pressure determining the structure of its bacterial community. Furthermore, possibly the sponge together with its specific microbial community prevents the establishment of other microorganisms in the sponge body. Nevertheless, some studies show that sponge-associated bacterial communities may suffer modifications according to environmental conditions [7], suggesting that although the relationship among bacteria and sponge may be specific, it may also show aspects of dynamism.

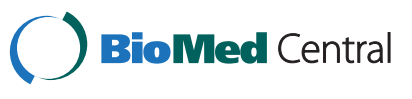

(c) 2014 O'Connor-Sánchez et al.; licensee BioMed Central. This is an Open Access article distributed under the terms of the Creative Commons Attribution License (http://creativecommons.org/licenses/by/4.0), which permits unrestricted use, distribution, and reproduction in any medium, provided the original work is properly credited. The Creative Commons Public Domain Dedication waiver (http://creativecommons.org/publicdomain/zero/1.0/) applies to the data made available in this article, unless otherwise stated. 
Numerous studies have reported the existence of spongespecific 16S ribosomal RNA gene sequence clusters, describing bacteria found in sponges but very rare in surrounding environments, like sediments or water [8]. The diversity and specificity of microbial communities in marine organisms is a key aspect of the ecology and evolutionary relationships between both the eukaryotic hosts and their associated prokaryotes. To date, 32 major bacterial phyla and several possibly novel spongeassociated bacterial communities have been identified [9]. Nevertheless, most studies have focused on sponges of high latitudes and very little is known about the structure of microbial communities associated with sponges of tropical seas.

The recent advent of massively parallel sequencing technologies has revolutionized microbial diversity and ecology studies. The gene encoding the small-subunit of the rRNA serves as a prominent tool for the phylogenetic analysis and classification of bacteria, owing to its high degree of conservation and its fundamental function in living organisms [10]. Pyrosequencing of this gene has proved to be a cost-effective method for the characterization of bacterial communities and, although it may be subject to a moderate bias [11], it is widely used to get a cultivation-independent general view about the phylogenetic profile of bacterial communities (e.g. [8]).

The aim of the present work was to analyze by $16 \mathrm{~S}$ tag-pyrosequencing assessment, the bacterial community structures of three sympatric marine organisms (two sponges and one zoanthid) and the sediments beneath them in a location of the Caribbean Sea.

\section{Results and discussion}

A total of 26,959 rRNA quality sequences with an average read length of 466 bp were generated through the tag-pyrosequencing. At phylum level, all the samples had a similar number of OTUs, ranging from 44 to 49 , with exception of the sponge Hyrtios, which had only 28. Nevertheless, at species level, the sediments showed a larger number of OTUs (441) than did the animal samples. The zoanthid Palythoa had 385 OTUs, while the sponges Aiolochroia and Hyrtios had 279 and 127 respectively (Table 1).
Chao 1 richness estimator suggests that most of the estimated diversity contained within these communities was captured by our sequencing efforts; even in the case of the sediments, where less reads were generated. Actually, at phylum level, the Chao 1 index coincides with the number of detected OTUs for all the samples. At species level, the sediments had the highest diversity predicted by Chao1 (460), while the sponge Hyrtios showed the lowest (164).

The Shannon diversity index values $\left(H^{\prime}\right)$, both at the phylum and species levels, suggest that the sediments held a higher bacterial diversity than the marine organisms living right above them; among which the zoanthid Palythoa had about the same bacterial diversity at species level than the sponge Aiolochroia and a more diverse bacterial community than the sponge Hyrtios. The sediments also presented higher evenness values than the animal samples; meaning that they had not only a higher number of taxa, but that their relative abundances were more homogeneous; thus making them the most diverse sample in this study. The higher bacterial diversity observed in the sediments is not surprising and has been described before [12]; it is also most likely the result of the sediments being subjected to more variable environmental conditions than the inside of the animal tissues, where highly selective conditions should prevail; furthermore, marine sediments may represent an environment with a higher number of microniches than those in animal tissue. All the observed values in our sponges are typically found in sponge microbiomes (e.g. [13]), which supports the former hypothesis.

All the generated reads were classified as belonging to the domain Bacteria. The reads from all the four samples together represented a total of 16 phyla (Figure 1A), out of which 12 had a relative abundance of $>1 \%$ in at least one sample. The phyla Chlorobi, TM7 and Tenericutes were only observed in the sediments sample, while the phylum Deinococcus-Thermus was only found in the zoanthid Palythoa and in the sponge Aiolochroia, and the only sample where the phylum Chlamydiae was not detected was the sponge Hyrtios. All the other phyla were present in the four samples. The two most

Table 1 General analysis of the pyrosequencing-derived datasets

\begin{tabular}{|c|c|c|c|c|c|c|c|c|c|c|}
\hline \multirow[b]{2}{*}{ Sample } & \multirow[b]{2}{*}{ \# Reads } & \multirow[b]{2}{*}{ Av seq len } & \multicolumn{4}{|c|}{ 20\% Dissimilarity } & \multicolumn{4}{|c|}{ 3\% Dissimilarity } \\
\hline & & & \# OTUs & Chao I & Shannon $\left(H^{\prime}\right)$ & Evenness & \# OTUs & Chao I & Shannon $\left(H^{\prime}\right)$ & Evenness \\
\hline Sediments & 2,348 & 413 & 45 & 45 & 2.95 & 0.77 & 441 & 460 & 5.52 & 0.90 \\
\hline Palythoa & 12,073 & 478 & 44 & 44 & 2.72 & 0.72 & 385 & 411 & 3.98 & 0.66 \\
\hline Aiolochroia & 6,439 & 464 & 49 & 49 & 2.74 & 0.70 & 279 & 308 & 3.95 & 0.70 \\
\hline Hyritios & 6,099 & 466 & 28 & 28 & 1.30 & 0.39 & 127 & 164 & 1.67 & 0.34 \\
\hline
\end{tabular}

The number of OTUs, Shannon diversity, Chao I and evenness were analyzed at 20\% (the phylum level) and 3\% (the species level) sequence dissimilarity for each sample. 


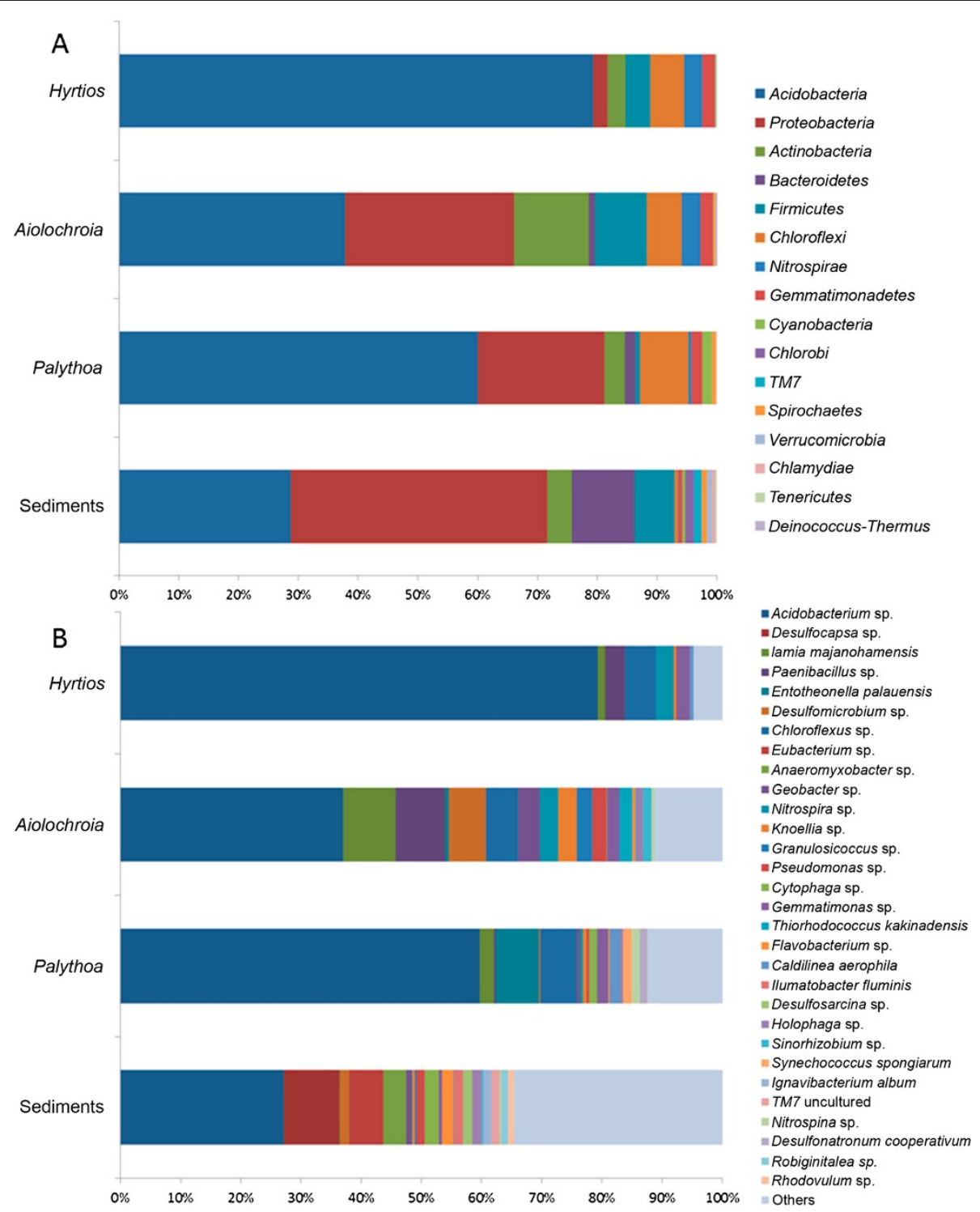

Figure 1 Bacterial distribution among the different marine samples. Percentage of different bacteria at $\mathbf{A}$ ) the phylum, and $\mathbf{B}$ ) the species level (20\% and 3\%, respectively) present in the three marine organisms and sediment sample from the Mexican Caribbean. Acidobacteria dominate all three marine organisms while Proteobacteria dominate the marine sediment sample.

dominant phyla in all the samples were Acidobacteria and Proteobacteria. Together, both accounted for more than two thirds of the total phyla present in each sample (Figure 1A). The third most abundant phylum within the sediments was Bacterioidetes, with 10\%, while in the animal samples it showed considerably lower abundances, ranging from $0.06 \%$ to $1.77 \%$. In the zoanthid and in the sponge Hyrtios, the third most abundant phylum was Chloroflexi ( $8 \%$ and $6 \%$ respectively), while in Aiolochroia, this rank was taken by Actinobacteria (12\%). All the phyla found in the animal samples have been previously reported as part of sponge microbiomes [8] while some phyla commonly found in sponge microbiomes, like Planctomycetes and the candidate phylum
Poribacteria, were not observed when using the RDP pipeline presented in this study.

The most outstanding difference in the bacterial community structure between the sediments and the animal samples was that while the sediments were dominated by Proteobacteria, the animal samples were strongly dominated by Acidobacteria. To our knowledge, this is the first report of Acidobacteria reaching abundances up to $79 \%$ in a sponge microbiome, where the dominant phyla that have been reported are either Proteobacteria (e.g. $[9,14])$ or Chloroflexi $[2,13]$.

Another surprising finding in this work was that at 3\% dissimilarity, Acidobacteria grouped in only one cluster (Figure 1B). However, when closely analyzing this data 
using the program Qiime [15], which uses the "greengenes" database (http://greengenes.lbl.gov/cgi-bin/nphindex.cgi), it was seen that this cluster contained 13 OTUs represented by uncultivated clones, and Candidatus Solibacter (Additional file 1: Figure S1). Nevertheless it is clear that this group contains only bacteria of the phylum Acidobacterium. In contrast, the phylum Proteobacteria split into several species, supporting previous observation about this phylum being one of the most diverse in sponges [6]. Due to the species partitioning observed in Proteobacteria, the genus Acidobacterium (phylum Acidobacteria, class Acidobacteria) was the most abundant in all the samples we tested, including the sediments (Figure 1B).

To our knowledge, there are only two previous studies on the bacterial community structures in sponges of the genus Hyrtios. (i) Schmitt et al. [6] studied the microbiome of three Hyrtios species: Hyrtios sp. collected in the Great Barrier Reef (Australia), Hyrtios altum collected in Guam (Northern Pacific Ocean), and Hyrtios erectus collected in the Red Sea. Although their analyses were not reported at the species level, the study does not reveal a clear correlation between microbial community structure and host phylogeny and suggests that geographic location may have a greater effect on microbial community structure than does the identity of the host sponge. (ii) Recently, Jeong et al. [13] studied the bacterial community structure present in two samples of Hyrtios erectus collected in Micronesia, where Acidobacteria represented only $10-20 \%$ of the total bacterial abundance in the sponges; far from the $79 \%$ observed in the Hyrtios sample in the present study. Our data strengthens the hypothesis that, although spongeassociated microbial communities may have some degree of host specificity, environmental conditions may exert a stronger influence on bacterial selection, thus the bacterial community structures of sponge microbiomes can have variations according to the geographic location where the organism is settled.

Meanwhile, only one study has been done on the microbiome of a zoanthid. Sun et al. [16] analyzed Palythoa australiae samples collected in the South China Sea and found that Proteobacteria was the most abundant phylum in that organism with a relative abundance of $58.6 \%$, followed by Chloroflexi (12\%) and Actinobacteria (10\%). Acidobacteria accounted for only $6 \%$ of the phyla they detected; in contrast with the $60 \%$ that we found in our zoanthid sample. As for sediment samples, our results agree with previous studies on the community structure in sea sediments (e.g. [17]), where Proteobacteria has been reported as the dominant phylum.

Our study suggests that sympatric samples may share some patterns on bacterial community structure and that the geographic location may have an influence as strong -or even stronger- than the phylogenetic relationship among their host organisms.

Members of the phylum Acidobacteria have been observed in many different habitats. Their phylogenetic diversity, ubiquity and abundance suggest that they have an important ecological role and an extensive metabolic versatility [18]. However, the genetic and physiological information regarding Acidobacteria is very scarce, as the majority of its members have not been cultivated and they have only been identified by their $16 \mathrm{~S}$ rDNA sequences. Currently, only 17 genome sequences from this phylum are publicly available [19].

\section{Conclusions}

Our results suggest that the environmental conditions in the sampled location of the Caribbean Sea, together with the conditions in the tissue of the studied samples, exerted a selective pressure favoring bacteria from the genus Acidobacterium. There is a possibility that the host, together with its associated Acidobacteria creates conditions that strongly inhibit the proliferation of other taxa (e.g. by producing secondary metabolites). Further work would be necessary to test these hypotheses, and support the study of these marine invertebrate genera as a source of novel marine natural products. Our study is a first insight into the microbiome of sessile marine invertebrates from the Mexican Caribbean using cultivation independent methods, and it may serve to formulate future hypotheses that contribute to a better scientific understanding of the marine organisms-microbiome interactions and their biotechnological potential.

\section{Methods}

Two sponges identified as Aiolochroia sp. (phylum Porifera, class Demospongias, order Verongida) and Hyrtios sp. (phylum Porifera, class Demospongias, order Dictyoceratida), one zoanthid identified as Palythoa sp. (phylum Cnidaria, class Anthozoa, order Zoanthidea), and a sediment sample, were collected by scuba diving at a depth of about 4-10 $\mathrm{m}$ in the Mexican area of the Caribbean Sea, in the reefs surrounding the lagoon of Banco Cinchorro ( $18^{\circ} 23.66 \mathrm{~N} ; 87^{\circ} 24.447 \mathrm{~W}$ ), in July 2012. The three sampled organisms and the sediments were collected very near to each other, within a radius of about $1 \mathrm{~m}$. The four samples were collected aseptically, enclosed in sterile bags, frozen at $-20^{\circ} \mathrm{C}$, and immediately transported to the laboratory.

Animal samples were then thawed and cut into small pieces and homogenized in a sterilized mortar. Metagenomic DNA was extracted according to the method described by Taylor et al. [20]. The DNA from the sediment sample was extracted following the method reported by Rojas-Herrera et al. [21]. 
Purified metagenomic DNA was submitted to the Research and Testing Laboratory (RTL) (Lubbock, TX, USA) for tag-pyrosequencing. Bacterial tag-encoded FLX amplicon pyrosequencing (bTEFAP) was performed as described previously using bacterial universal primers Gray28F (5'TTTGATCNTGGCTCAG-3') and Gray519R (5'-GTNTT ACNGCGGCKGCTG-3') primers [22]. Sequencing was based on RTL protocols (www.researchandtesting.com).

Following sequencing, all failed sequence reads, low quality sequence ends and tags and primers were removed and sequence collections depleted of any nonbacterial ribosome sequences and chimeras using the B2C2 software [23], as described previously [24]. To determine the identity of bacteria in the remaining sequences, these were denoised, assembled into clusters and queried using a distributed BLASTn.NET algorithm against a database of high-quality $16 \mathrm{~S}$ bacterial sequences derived from NCBI. Database sequences were characterized as high-quality based upon criteria similar to those utilized by RDP [25]. Using a .NET and $\mathrm{C \#}$ analysis pipeline, the resulting BLASTn outputs were compiled and validated using taxonomic distance methods and data reduction analysis was performed as described previously [24]. Based upon the above BLASTn-derived sequence identity (percent of totallength query sequence which aligns with a given database sequence) and validated using taxonomic distance methods, the bacterial sequences were classified at the appropriate taxonomic levels based upon the following criteria: sequences with identity scores (relative to known or well characterized $16 \mathrm{~S}$ sequences) greater than 97\% identity ( $<3 \%$ divergence) were resolved at the species level, and $77 \%$ to $80 \%$ at the phylum level. Sequencing reads were aligned and clustered following the Ribosomal Database Project (RDP-Release 10) pyrosequencing pipeline (http://pyro.cme.msu.edu/). Shannon, Chao 1, and evenness indices were obtained using the RDP tools.

All the $16 \mathrm{~S}$ rRNA gene sequences were deposited in the NCBI Sequence Read Archive (SRA) under the Bioproject PRJNA256178 (http://www.ncbi.nlm.nih.gov/biosample?Lin kName=bioproject_biosample_all \&from_uid = 256178).

All the experimental research that is reported in the manuscript has been performed with the approval of an appropriate ethics committee. There was not experimental research neither on humans nor on animals.

\section{Additional file}

Additional file 1: Operational taxonomic units (OTUs) at 97\% 16S rRNA sequence similarity belonging to the phylum Acidobacteria that were observed in the three sympatric marine organisms studied.

\section{Competing interests}

The authors declare that they have no competing interests.

\section{Authors' contributions}

All authors have contributed equally to this work. All authors read and approved the final manuscript.

\section{Acknowledgements}

The authors would like to thank Dr. Joseph Pawlik from the University of North Carolina Wilmington for his kind invitation to participate in the oceanographic expedition aboard the R/V Walton Smith as well as all the ship crew and members for their support towards this project. We would like to acknowledge Jan Vicente Raczkowski from the University of Maryland Center for Environmental Science for his prompt identification of our marine organisms. We also thank Dr. Reynaldo C Pless-Elling for his suggestions and edits to the manuscript. All samples were taken under SRE permit: CTC-06809 and CONAPESCA permit: DAPA/2/06504/11//612/1608. The work for this publication was partially supported by the CICY Fiscal Fund 60210, the fund FOMIX-Yucatán165026 the CONACYT "Iniciación a la Investigación" fellowship \#1039200015 and by UNAM Facultad de Química PAIP 2011-2012 fund.

\section{Author details}

${ }^{1}$ Unidad de Biotecnología. Centro de Investigación Científica de Yucatán A.C, Calle 43 \# 130, Chuburná de Hidalgo, 97200 Mérida, Yucatán, México. ${ }^{2}$ Facultad de Química - Unidad Académica Sisal, Universidad Nacional Autónoma de México, Puerto de abrigo s/n, Municipio de Hunucmá, 97356 Sisal, Yucatán, México. ${ }^{3}$ Departamento de Ciencias de la Sustentabilidad, El Colegio de la Frontera Sur - Unidad Campeche, Campeche, México.

Received: 13 September 2014 Accepted: 27 November 2014 Published: 10 December 2014

\section{References}

1. Graca AP, Bondoso J, Gaspar H, Xavier JR, Monteiro MC, de la Cruz M, Oves-Costales D, Vicente F, Lage OM: Antimicrobial activity of heterotrophic bacterial communities from the Marine Sponge Erylus discophorus (Astrophorida, Geodiidae). PLoS One 2013, 8(11):e78992. doi:10.1371/journal. pone.0078992.

2. Montalvo NF, Davis J, Vicente J, Pittiglio R, Ravel J, Hill RT: Integration of culture-based and molecular analysis of a complex sponge-associated bacterial community. PLoS One 2014, 9(3):e90517. doi:10.1371/journal. pone.0090517.

3. Dupont S, Carre-Mlouka A, Domart-Coulon I, Vacelet J, Bourguet-Kondracki ML: Exploring cultivable Bacteria from the prokaryotic community associated with the carnivorous sponge Asbestopluma hypogea. FEMS Microbio/ Ecol 2014, 88:160-174. doi:10.1111/1574-6941.12279.

4. Hentschel U, Hopke J, Horn M, Friedrich AB, Wagner M, Hacker J, Moore BS: Molecular evidence for a uniform microbial community in sponges from different oceans. Appl Environ Microb 2002, 68(9):4431. doi:10.1128/AEM. 68.9.4431-4440.

5. Taylor MW, Radax R, Steger D, Wagner M: Sponge-associated microorganisms: evolution, ecology, and biotechnological potential. Microbiol Mol Biol R 2007, 71(2):295-347. doi:10.1128/MMBR. 00040-06.

6. Schmitt S, Tsai P, Bell J, Fromont J, llan M, Lindquist N, Perez T, Rodrigo A, Schupp PJ, Vacelet J, Webster N, Hentschel U, Taylor MW: Assessing the complex sponge microbiota: core, variable and species-specific bacterial communities in marine sponges. ISME 2012, 6(3):564-576. doi:10.1038/ ismej.2011.116.

7. Mohamed NM, Enticknap JJ, Lohr JE, Mcintosh SM, Hill RT: Changes in bacterial communities of the marine sponge Mycale laxissima on transfer into aquaculture. Appl Environ Microb 2008, 74(4):1209-1222. doi:10.1128/ AEM. 02047-07.

8. Taylor MW, Tsai P, Simister RL, Deines P, Botte E, Ericson G, Schmitt S, Webster NS: "Sponge-specific" bacteria are widespread (but rare) in diverse marine environments. ISME J 2013, 7(2):438-443. doi:10.1038/ismej.2012.111.

9. Alex A, Silva V, Vasconcelos V, Antunes A: Evidence of unique and generalist microbes in distantly related sympatric intertidal marine sponges (Porifera: Demospongiae). PLoS One 2013, 8(11):e80653. doi:10.1371/journal.pone.0080653.

10. Vos M, Quince C, Pijl AS, DE Hollander M, Kowalchuk GA: A comparison of rpoB and $16 \mathrm{~S}$ rRNA as markers in pyrosequencing studies of bacterial diversity. PLoS One 2012, 7(2):e30600. doi:10.1371/journal.pone.0030600. 
11. Kumar PS, Brooker MR, Dowd SE, Camerlengo T: Target region selection is a critical determinant of community fingerprints generated by $16 \mathrm{~S}$ pyrosequencing. PLoS One 2011, 6(6):e20956. doi:10.1371/journal. pone.0020956.

12. Aravindraja C, Viszwapriya D, Pandian KS: Ultradeep $16 \mathrm{~S}$ rRNA sequencing analysis of geographically similar but diverse unexplored marine samples reveal varied bacterial community composition. PLoS One 2013, 8(10):e76724. doi:10.1371/journal.pone.076724.

13. Jeong I-H, Kim K-H, Lee H-S, Park J-S: Analysis of bacterial diversity in sponges collected from Chuuk and Kosrae islands in Micronesia. J Microbiol 2014, 52(1):20-26. doi:10.1007/s12275-014-3619-X.

14. Jackson SA, Kennedy J, Morrissey JP, O'Gara F, Dobson ADW: Pyrosequencing reveals diverse and distinct sponge-specific microbial communities in sponges from a single geographical location in Irish Waters. Microb Ecol 2012, 64:105-116. doi:10.1007/s00248-011-0002-x.

15. Caporaso JG, Kuczynski J, Stombaugh J, Bittinger K, Bushman FD, Costello EK, Fierer N, Gonzalez-Pena A, Goodrich JK, Gordon JI, Huttley GA, Kelley ST, Knights D, Koenig JE, LEY RE, Lozupone CA, Mcdonald D, Muegge BD, Pirrung M, Reeder J, Sevinsky JR, Turnbaugh PJ, Walters WA, Widmann J, Yatsunenko T, Zaneveld J, Knight R: QIIME allows analysis of high-throughput community sequencing data. Nat Methods 2010, 7:335-336. doi:10.1038/nmeth.f.303.

16. Sun W, Zhang F, He L, Li Z: Pyrosequencing reveals diverse microbial community associated with the ZoanthidPalythoa australiaefrom the South China Sea. Microb Ecol 2014. doi:10.1007/s00248-014-0395-4.

17. Gao F, Li F, Tan J, Yan J, Sun H: Bacterial community composition in the gut content and ambient sediment of sea cucumber Apostichopus japonicus revealed by 16S rRNA Gene Pyrosequencing. PLoS One 2014, 9(6):e100092. doi:10.1371/journal.pone.0100092.

18. Quaiser A, Ochsenreiter T, Lanz C, Schuster SC, Treusch AH, Eck J, Christa Schleper C: Acidobacteria form a coherent but highly diverse group within the bacterial domain: evidence from environmental genomics. Mol Microbiol 2003, 50(2):563-575. doi:10.1046/j.1365-2958.2003.03707.x.

19. Stamps BW, Losey NA, Lawson PA, Bradley S, Stevenson BS: Genome sequence of Thermoanaerobaculum aquaticum MP- $01^{\top}$, the first cultivated member of Acidobacteria subdivision 23, isolated from a hot spring. Genome Announc 2014, 2(3):e00570-14. doi:10.1128/genomeA. 00570-14.

20. Taylor MW, Schupp PJ, Dahllöf I, Kjelleberg S, Peter D, Steinberg PD: Host specificity in marine sponge-associated bacteria, and potential implications for marine microbial diversity. Environ Microbiol 2004, 6(2):121-130. doi:10.1046/j.1462-2920.2003.00545.x.

21. Rojas-Herrera R, Narváez-Zapata J, Zamudio-Maya M, Mena-Martínez ME: A simple silica-based method for metagenomic DNA extraction from soil and sediments. Mol Biotechnol 2008, 40:13-17. doi:10.1007/s12033-008-9061-8.

22. Dowd SE, Callaway TR, Wolcott RD, Sun Y, Mckeehan T, Hagevoort RG, Edrington TS: Evaluation of the bacterial diversity in the feces of cattle using $16 \mathrm{~S}$ rDNA bacterial tag-encoded FLX amplicon pyrosequencing (bTEFAP). BMC Microbiol 2008, 8:125. doi:10.1186/1471-2180-8-125.

23. Gontcharova V, Youn E, Wolcott RD, Hollister EB, Gentry TJ, Dowd SE: Black box chimera check (B2C2): a windows-based software for batch depletion of chimeras from bacterial 16S rRNA gene datasets. Open Microbiol J 2010, 4:47-52.

24. Ishak HD, Plowes R, Sen R, Kellner K, Meyer E, Estrada DA, Dowd SE, Mueller UG: Bacterial diversity in Solenopsis invicta and Solenopsis geminata ant colonies characterized by $16 \mathrm{~S}$ amplicon 454 pyrosequencing. Microb Ecol 2011, 61:821-831. doi:10.1007/s00248-010-9793-4.

25. Cole JR, Wang Q, Cárdenas E, Fish J, Chai B, Farris RJ, Kulam-Syed-Mohideen AS, Mcgarrell DM, Marsh T, Garrity GM, Tiedje JM: The ribosomal database project: improved alignments and new tools for rRNA analysis. Nucleic Acids Res 2009, 37:D141-D145.

doi:10.1186/0717-6287-47-67

Cite this article as: O'Connor-Sánchez et al:: Acidobacteria appear to dominate the microbiome of two sympatric Caribbean Sponges and one Zoanthid. Biological Research 2014 47:67.

\section{Submit your next manuscript to BioMed Central and take full advantage of:}

- Convenient online submission

- Thorough peer review

- No space constraints or color figure charges

- Immediate publication on acceptance

- Inclusion in PubMed, CAS, Scopus and Google Scholar

- Research which is freely available for redistribution

Submit your manuscript at www.biomedcentral.com/submit
() Biomed Central 